\title{
SISTEM PENDUKUNG KEPUTUSAN \\ PEMBUKAAN JARINGAN TRAYEK ANGKUTAN KOTA DENGAN METODE SIMPLE ADDITIVE WEIGHTING
}

\author{
Amula Arni ${ }^{1}$, Rakhmad Kuswandhie ${ }^{2}$ \\ ${ }^{1}$ Sistem Informasi, STMIK Bina Nusantara Jaya Lubuklinggau \\ Jalan Yos Sudarso No 97 A Kota Lubuklinggau, Sumatera Selatan \\ E-mail :amula_arni01@gmail.com ${ }^{1)}$,ma2dxl@gmail.com ${ }^{2)}$
}

\begin{abstract}
The Transportation and Information Service Office of Lubuklinggau City is one of the agencies tasked with opening and diverting the city transportation route network and determining the number of fleets and city transportation fares. In carrying out its duties, the Transportation Agency still uses manual methods so that there are frequent delays in taking needs. This is very unexpected because conditions in the field require decisions that are produced in the right time. Based on the description above, it is necessary to have a system that can assist Transportation Agency in making decisions without reducing the quality of the decisions produced, this system is called the Decision Support System (SPK) is expected to be able to assist the Department of Transportation in processing and analyzing data that can be useful in opening and diverting urban transport routes. The method used by the system is the SAW method, the purpose of making this system is to assist in making decisions to determine the best route network to be used.
\end{abstract}

\section{Intisari}

Dinas Perhubungan Komunikasi dan Informatika Kota Lubuklinggau, adalah instansi yang bertugas salah satunya membuka dan mengalihkan jaringan trayek angkutan kota serta menentukan jumlah armada dan tarif angkutan kota. Dalam melaksanakan tugasnya Dishub masih menggunakan cara yang manual sehingga sering terjadinya keterlambatan dalam pengambilan kebutusan. Hal ini sangat tidak di harapkan karena kondisi di lapangan memerlukan keputusan yang dihasilkan dalam waktu yang tepat.Berdasarkan uraian di atas, maka perlu adanya suatu sistem yang dapat membantu Dishub dalam pengambilan keputusan tanpa mengurangi kualitas dari keputusan yang dihasilkan, sistem ini disebut Sistem Pendukung Keputusan (SPK) diharapkan dapat membantu Dishub dalam melakukan pengolahan dan analisis data yang dapat berguna dalam membuka dan mengalihkan jaringan trayek angkutan kota. Metode yang digunakan sistem adalah metode SAW, tujuan dari pembuatan sistem ini adalah untuk membantu dalam pengambilan keputusan untuk menentukan jaringan trayek terbaik yang akan digunakan.

Kata Kunci :Route Network, Decision Support System, SAW

\section{PENDAHULUAN}

\section{Latar Belakang}

Pada suatu instansi maupun perusahaan pengambilan keputusan merupakan tindakan yang harus diikuti untuk memecahkan suatu masalah. Maka dari itu sistem pendukung keputusan sangat diperlukan untuk memecahkan masalah tersebut, sistem tersebut adalah suatu sistem berbasis komputer yang membantu mengambil keputusan. Sebagai seorang manajer tentunya dalam pengambilan suatu keputusan harus secara baik efisien dan menghasilkan produk yang bermanfaat. Agar keputusan yang diambil sesuai harapan maka hal-hal yang berkaitan harus saling bekerja sama dan saling melengkapi. Dapat juga dikatakan sebagai sistem komputer yang mengolah data menjadi informasi untuk mengambil keputusan dari masalah semi-terstruktur yang spesifik.

Dinas Perhubungan Komunikasi dan Informatika Kota Lubuklinggau adalah instansi pemerintahan yang salah satu tugasnya membuka dan mengalihkan jaringan trayek angkutan kota. Dalam melaksanakan tugasnya, Dishub membutuhkan waktu yang lama, karena pekerjaan merangkum, melakukan perhitungan dan analisis terhadap data dan variabel yang didapatkan dari survey, masih dilakukan secara manual yaitu data jalan yang telah diterima oleh pihak Dishub akan di simpan kemudian akan dilakukan perhitungan yang cukup sederhana atau bahkan hanya lewat insting saja sehingga kualitas keputusan pun perlu dipertanyakan. Cara inilah yang sering menjadi 
faktor utama keterlambatan pengambilan keputusan, sistem pendukung keputusan sebagai sistem informasi berbasis komputer yang adaptif, interaktif, fleksibel, yang secara khusus dikembangkan untuk mendukung solusi dari pemasalahan manajemen yang tidak terstruktur untuk meningkatkan kualitas pengambilan keputusan. Dengan demikian dapat ditarik satu definisi tentang sistem pendukung keputusan yaitu sebuah sistem berbasis komputer yang adaptif, fleksibel, dan interaktif yang digunakan untuk memecahkan masalah-masalah tidak terstruktur sehingga meningkatkan nilai keputusan yang diambil[1].Metode yang digunakan dalam sistem pendukung keputusan ini adalah $S A W, S A W$ ini dipilih karena dapat menentukan nilai bobot untuk setiap atribut, kemudian dilanjutkan dengan proses perankingan yang akan menyeleksi alternatif terbaik dari sejumlah alternatif, dalam hal ini alternatif yang dimaksud adalah kelayakan jaringan trayek berdasarkan kriteria-kriteria yang ditentukan.

Berdasarkan uraian diatas, maka penulis membantu pihak Dishub dalam menentukan alternatif terbaik dalam menentukan kelayakan pembukaan jaringan trayek angkutan kota dengan cara membuat suatu sistem "SISTEM PENDUKUNG KEPUTUSAN PEMBUKAAN JARINGAN TRAYEK ANGKUTAN KOTA DINAS PERHUBUNGAN KOMUNIKASI DAN INFORMATIKA KOTA LUBUKLINGGAU DENGAN METODE SAW (SIMPLE ADDITIVE WEIGHTING)".

\section{Tujuan Penelitian}

Adapun tujuan dari penelitian adalah membuat suatu sistem pendukung keputusan pembukaan jaringan trayek angkutan kota Dinas Perhubungan Komunikasi dan Informatika Kota Lubuklinggau dengan metode simple additive weighting.

\section{LANDASAN TEORI}

\section{Pengertian Sistem Pendukung Keputusan}

Sistem pendukung keputusan atau Decision Suport System (DSS) adalah sistem informasi interaktif yang menyediakan informasi, pemodelan dan pemanipulasian data yang digunakan untuk membuat pengambilan keputusan pada situasi yang semi terstruktur dimana tak seorang pun tahu secara pasti bagaimana keputusan seharusnya dibuat[2].

Keputusan manajemen sering dikelompokkan menjadi 3 bagian, yaitu :

1) Keputusan terstruktur (structured decision) : keputusan yang dilakukan secara berulangulang dan bersifat rutin. Prosedur untuk pengambilan keputusan sangat jelas.
Keputusan ini dilakukan terutama dilakukan pada manajemen tingkat bawah. Misalnya, keputusan pemesanan barang dan keputusan penagihan piutang.

2) Keputusan semiterstruktur (semistructured decision): keputusan yang dapat ditangani oleh komputer maupun yang tetap harus dilakukan oleh pengambil keputusan. Misalnya, mengevaluasi kredit, penjadwalan produksi, pengendalian sediaan.

3) Keputusan tak terstruktur (unstructured decision) : keputusan yang penanganannya rumit karena tidak terjadi berulang-ulang atau tidak selalu terjadi. Keputusan ini menuntut pengalaman dan berbagai sumber yang bersifat eksternal. Keputusan ini umumnya terjadi pada manajemen tingakat atas. Misalnya, pengembangan teknologi baru, keputusan untuk bergabung dengan perusahaan lain, dan perekrutan eksekutif.

\section{Pengertian Jaringan Trayek}

Jaringan trayek adalah kumpulan dari trayektrayek yang menjadi satu kesatuan jaringan pelayanan angkutan orang baik diperkotaan, antar kota dalam provinsi ataupun antar kota antar provinsi Menurut[3].

\section{Metode Penelitian}

\section{Metode Pengumpulan Data}

Ada beberapa metode pengumpulan data yang digunakan penulis untuk mendapatkan data-data yang sesuai dengan kebutuhan pada sistem informasi yang akan dihasilkan, data-data yang dimaksud meliputi:

1) Pengamatan (Observasi)

2) Wawancara (Interview)

\section{Metode Pengembangan Sistem}

Metode pengembangan sistem yang penulis gunakan yaitu prototyping. "Model Prototipe (prototyping model) dimulai dari pengumpulan kebutuhan pelanggan terhadap perangkat lunak yang akan dibuat. Lalu dibuatlah program prototipe agar pelanggan lebih terbayang dengan apa yang sebenarnya diinginkan. Program prototipe biasanya merupakan program yang belum jadi. Program ini biasanya menyediakan tampilan dengan simulasi alur perangkat perangkat lunak sehingga tampak seperti perangkat lunak yang sudah jadi. Program prototipe ini dievaluasi oleh pelanggan atau user sampai ditemukan spesifikasi yang sesuai dengan keinginan pelanggan atau user."

Berikut ini adalah gambar dari model prototipe[4]: 


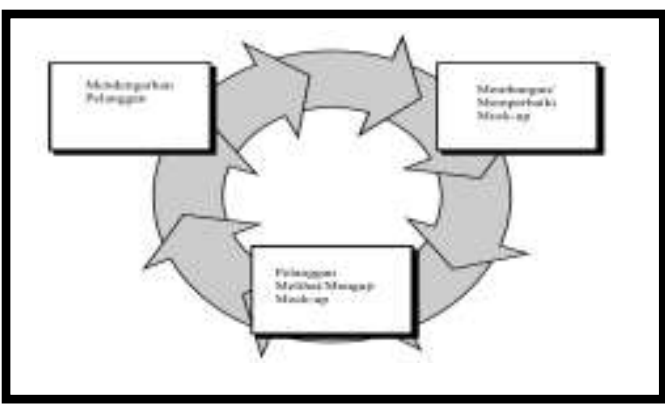

Gambar 1.Metode Prototype

a) Mendengarkan pelanggan

Dalam tahap ini penulis dan pihak Dinas Perhubungan Komunikasi dan Informatika Kota Lubuklinggau bertemu langsung untuk mengetahui permasalahan yang dihadapi, menentukan tujuan umum sistem, kebutuhan dan spesifikasi sistem yang akan dibangun serta gambaran-gambaran dari alur sistem yang akan dibangun.

b) Membangun /Memperbaiki Mock-up

Pada tahap ini penulis merancang prototipe sesuai dengan yang diinginkan oleh Dinas Perhubunngan Komunikasi dan Informatika Kota Lubuklinggau dari hasil pada tahap sebelumnya yakni tahap mendengarkan pelanggan.

c) Pelanggan Melihat/menguji Mock-up

Staff Dinas Perhubunngan Komunikasi dan Informatika Kota Lubuklinggau pada bagian Lalu Lintas dan Angkutan Jalan menguji coba dan mengevaluasi prototipe yang telah dibuatkan oleh penulis untuk memperjelas kebutuhan dari sistem yang diinginkan oleh pihak Dinas Perhubunngan Komunikasi dan Informatika Kota Lubuklinggau.

\section{Simple Additive Weighting Method (SAW)}

Metode SAW sering juga dikenal istilah metode penjumlahan terbobot. Konsep dasar metode SAW adalah mencari penjumlahan terbobot dari rating kinerja pada setap alternatif pada semua atribut. Metode SAW membutuhkan proses normalisasi matriks keputusan (X) ke suatu skala yang dapat diperbandingkan dengam semua rating alternatif yang ada[5].

$$
r_{i j}=\left\{\begin{array}{l}
\frac{x_{i j}}{\max x_{i j}} \\
\frac{\min x_{i j}}{x_{i j}}
\end{array}\right.
$$

Jika $\mathrm{j}$ adalah atribut keuntungan (henefit)

jika j adalah attribute biaya
Dimana $\mathrm{r}_{\mathrm{ij}}$ adalah rating kinerja ternormalisasi dari alternatif $A_{i}$ pada atribut $C_{j}: i=1,2, \ldots, m$ dan $j=$ $1,2, \ldots, n$. Nilai preferensi untuk setiap alternatif $\left(\mathrm{V}_{\mathrm{i}}\right)$ diberikan sebagai berikut:

Dimana

$\mathrm{r}_{\mathrm{ij}}=$ rating kinerja ternormalisasi $\operatorname{Max}_{\mathrm{ij}}=$ nilai maksimum dari setiap baris dan kolom

$\operatorname{Min}_{\mathrm{ij}}=$ nilai minimum dari setiap baris dan kolom $\mathrm{X}_{\mathrm{ij}}=$ baris dan kolom dari matriks Dengan $\mathrm{r}_{\mathrm{ij}}$ adalah rating kinerja ternormalisasi dari alternatif $A_{i}$ pada atribut $C_{j} ; i=1,2, \ldots m$ dan $j=$ $1,2, \ldots, n$.

Nilai preferensi untuk setiap alternatif $\left(\mathrm{V}_{\mathrm{i}}\right)$ diberikan sebagai:

Dimana :

$\mathrm{V}_{\mathrm{i}}=$ Nilai akhir dari alternatif

$\mathrm{w}_{\mathrm{j}}=$ Bobot yang telah ditentukan

$\mathrm{r}_{\mathrm{ij}}=$ Normalisasi matriks

Nilai $\mathrm{V}_{\mathrm{i}}$ lebih besar mengindikasikan bahwa alternatif $A_{i}$ lebih terpilih.

$$
V_{i}=\sum_{j=1}^{n} w_{j} r_{i j}
$$

\section{Metode Pengujian Perangkat Lunak}

Dalam pengujian perangkat lunak penulis menggunakan metode pengujian black box adalah pengujian aspek fundamental sistem tanpa memperhatikan struktur logika internal perangkat lunak. Metode ini digunakan untuk mengetahui apakah perangkat lunak berfungsi dengan benar. Pengujian black box merupakan metode perancangan data uji yang didasarkan pada spesifikasi perangkat lunak yang dibuat. Rosa A. S (2013).

\section{Rank Order Centroid (ROC)}

ROC didasarkan pada tingkat kepentingan atau prioritas dari kriteria. teknik ROC memberikan bobot pada setiap kriteria sesuai dengan ranking yang dinilai berdasarkan tingkat prioritas. Biasanya dibentuk dengan pernyataan "Kriteria 1 lebih penting dari kriteria 2, yang lebih penting dari kriteria 3" dan seterusnya hingga kriteria ke n, ditulis . Untuk menentukan bobotnya, diberikan aturan yang sama yaitu dimana merupakan bobot untuk kriteria[6]. Atau dapat dijelaskan sebagai berikut: 
Jika

$\mathrm{Cr} 1 \geq \mathrm{Cr} 2 \geq \mathrm{Cr} 3 \geq \ldots \geq \mathrm{Crn}$

Maka

$\mathrm{W} 1 \geq \mathrm{W} 2 \geq \mathrm{W} 3 \geq \ldots \geq \mathrm{Wn}$

$\mathrm{W}_{1}=\frac{1+\frac{1}{2}+\frac{1}{3}+\frac{1}{4}+\cdots+1 / k}{k}$
$\mathrm{~W}_{2}=\frac{0+\frac{1}{2}+\frac{1}{3}+\frac{1}{4}+\cdots+1 / k}{k}$

\section{ANALISIS DAN PERANCANGAN SISTEM}

\section{Analisis Sistem}

Hal-hal yang dianalisis pada tahap analisis sistem adalah analisis prosedur kerja, analisis pemecahan masalah, analisis kebutuhan data, kebutuhan fungsional, kebutuhan nonfungsional.

\section{Analisis Terdahulu}

Hasil observasi awal dari penelitian yang telah dilaksanakan pada Dinas Perhubungan Komunikasi dan Informatika Kota Lubuklinggau khususnya pada bagian Lalu Lintas dan Angkutan Jalan sebagai berikut:

1) Salah satu tugas bagian Lalu Lintas dan Angkutan Jalan bertugas mengelola dan melakukan perhitungan data-data jaringan trayek.

2) Sistem yang sedang berjalan dalam melakukan pendataan jalan yang akan dibuat jaringan trayek dan proses perhitungan untuk menentukan kelayakan pembukaan jaringan trayek masih menggunakan cara manual yaitu pertama-tama pegawai akan menentukan kriteria yang akan digunakan kemudian barula akan dilakukannya perhitungan dengan perkiraan saja apakah jaringan trayek layak atau tidak untuk dibuka.

3) Pembuatan laporan pembukaan jaringan trayek dilakukan dengan cara merekap data pemohon dan jaringan trayek pada Ms. Excel.

4) Pencarian data-data jaringan trayek dengan cara membuka catatan dalam buku besar.

5) Dinas Perhubungan Komunikasi dan Informatika Kota Lubuklinggau tidak menerapkan sistem pendukung keputusan pembukaan jaringan trayek Berbasis Komputer.

\section{Analisis Pemecahan Masalah}

Dari prosedur kerja untuk menentuan pembukaan jaringan trayek angkutan kota pada Dinas Perhubungan Komunikasi dan Informatika Kota Lubuklinggau dapat dilihat proses penentuan pembukaan jaringan trayek dan nilai untuk masingmasing kriteria belum ditentukan, sehingga memungkinkan terjadinya kesalahan pada saat pemberian nilai hasil seleksi yang didapat sehingga mengakibatkan pemberian nilai hasil seleksi yang cenderung kurang objektif. Masalahdalam penentuan pembukaan jaringan trayek ini merupakan masalah semi terstruktur, tidak rutin dilakukan dan tergantung kebutuhan. Untuk membantu menyelesaikan masalah-masalah semi terstruktur diperlukan sistem pendukung keputusan untuk proses perhitungan nilai hasil pada proses pembukaan jaringan trayek. Sistem ini dimaksudkan untuk mendukung dan meningkatkan pengambilan keputusan, namun tidak untuk menggantikan keputusan.

Berdasarkan sistem pendukung keputusan yang penulis tawarkan meliputi dua tahap yaitu proses data jalan/alternatif dan proses seleksi calon pembukaan jaringan trayek yang akan dibuka. Model SAW (Simple Additive Weighting) dalam prosesnya memerlukan kriteria yang akan dijadikan bahan perhitungan pada proses perankingan. Dari masing-masing kriteria tersebut akan ditentukan tingkat kepentingan kriteria dan bobot-bobotnya dengan menggunakan pembobotan ROC (Rank Order Centroid).

\section{Analisis Kebutuhan Data}

1) Data Primer

Sumber data primer pada penelitian ini adalah data yang didapat oleh penulis melalui wawancara langsung pada staff bagian lalulintas dan angkutan jalan, yang bertugas dalam penentuan dan pembukaan jaringan trayek angkutan kota.

2) Data Sekunder

Adapun sumber data sekunder yang didapat penulis dari penelitian ini adalah data yang diperoleh dari studi pustaka laporan penelitian yang pernah melakukan penelitian pada Dinas Perhubungan Komunikasi dan Informatika Kota Lubuklinggau dan dari laporan tahunan Dinas Perhubungan Komunikasi dan Informatika Kota Lubuklinggau.

\section{Kebutuhan Fungsional}

Adapun kebutuhan fungsional yang ada pada Sistem pendukung Keputusan ini yaitu:

1. Sistem ini dapat melakukan pengolahan data calon pembukaan jaringan trayek

2. Sistem dapat melakukan pengolahan data kriteria dan bobot yang akan digunakan dalam perhitungan nilai hasil pemilihan

3. Sistem dapat melakukan pengolahan data nilai hasil seleksi calon pembukaan jaringan trayek untuk mengitung ranking (nilai akhir) 
4. Sistem dapat menghasilkan laporan.

\section{Perancangan Sistem}

1. Use Case Diagram

Berikut ini merupakan usecase diagram pada aktor Kepala Dinas.

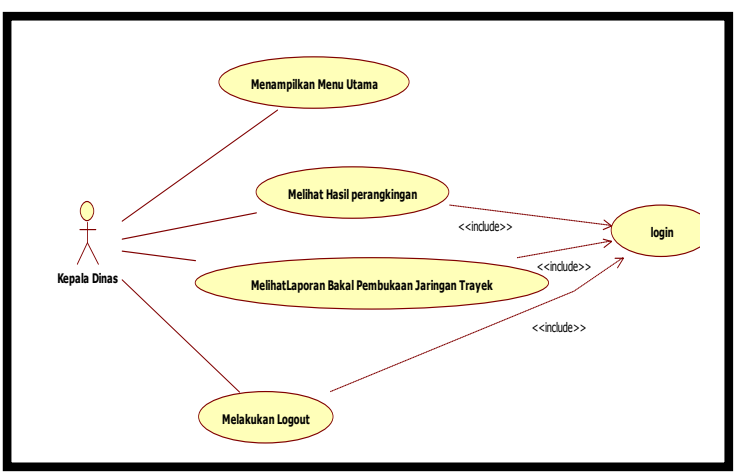

Gambar 5.Use Case Diagram Pada Aktor Kepala Dinas

2. Class Diagram

Berikut ini merupakan class diagram pada sistem yang akan dibangun

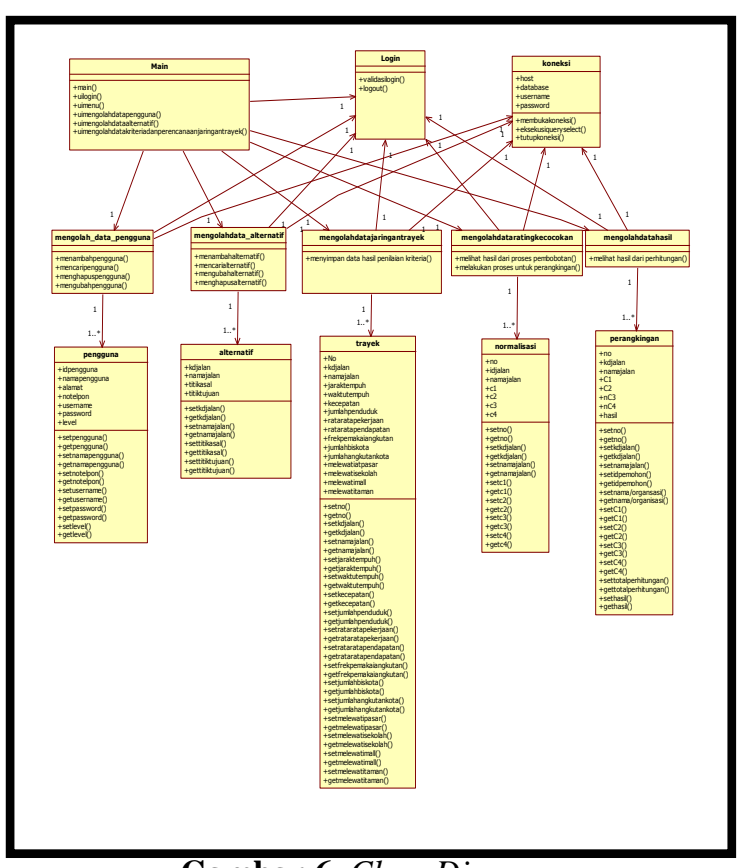

Gambar 6. Class Diagram

\section{IMPLEMENTASI}

\section{Arsitektur Sistem}

Arsitektur sistem adalah istilah untuk menyatakan bagaimana mendefinisikan komponenkomponen yang terdapat didalam sistem. Adapun arsitekur sistem pendukung keputusan pembukaan jaringan trayek angkutan kota Dinas Perhubungan
Komunikasi dan Informatika Kota Lubuklinggau adalah sebagai berikut

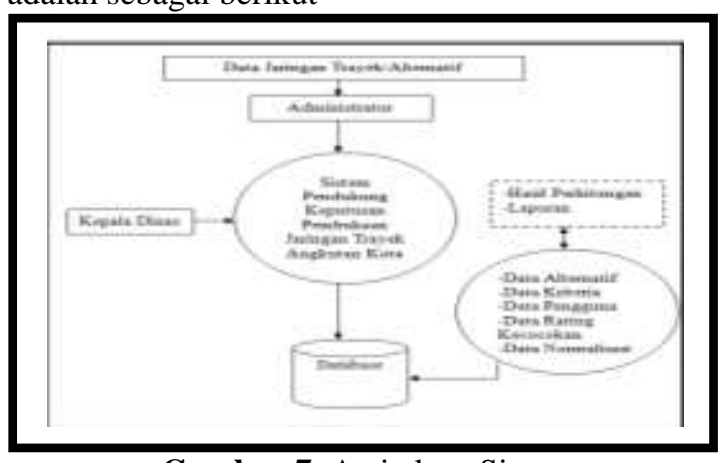

Gambar 7. Arsitektur Sistem

\section{Uraian Hasil Yang Didapat}

Berikut adalah contoh perhitungan manual menggunakan metode Saw (Simple Additive Weighting) berdasarkan tiga alternatif yang ada untuk pembukaan jaringan trayek angkutan kota:

$\mathrm{C} 1=$ Penduduk

$\mathrm{C} 2=\mathrm{Jalan}$

C3= Tempat Umum

C4= Kompetitor

Berdasarkan Tingkat kepentingan kriteria maka dapat dibobotkan sebagai berikut: $\mathrm{C} 1=0,521$

$\mathrm{C} 2=0,271$

$\mathrm{C} 3=0,145$

$\mathrm{C} 4=0,063$

Ada Tiga Alternatif Pembukaan Jaringan Trayek Angkutan Kota, yaitu:

A1=Terminal kalimantan-jl.yos sudarso-tbpinginterminal type A-sp.periuk

$\mathrm{A} 2=$ Terminal Kamlimantan-j1.lintas sumantraterminal satelit-megang-siring agung-sp periuk A3= Terminal kalimantan-jl.garuda-terminal type c watas-megang-siring agung-periuk.

Tabel 1 Tabel kecocokan alternatif pada kriteria

\begin{tabular}{|l|l|l|l|l|}
\hline \multirow{2}{*}{$\begin{array}{l}\text { Alternati } \\
\text { f }\end{array}$} & \multicolumn{4}{|c|}{ Kriteria } \\
\cline { 2 - 5 } A1 & $\mathrm{C} 1$ & $\mathrm{C} 2$ & $\mathrm{C} 3$ & $\mathrm{C} 4$ \\
\hline A2 & 0.611 & 0.611 & 0.521 & 0.611 \\
\hline A3 & 0.278 & 0.278 & 0.271 & 0.278 \\
\hline
\end{tabular}

Proses normalisasi dibagi dengan maksimal dan minimal bobot pada setiap alternatif pada semua kriteria:

Matrik keputusan dibentuk dari tabel kecocokan

$\begin{array}{lllll} & 0.611 & 0.611 & 0.521 & 0.611 \\ \mathrm{x} & 0.278 & 0.278 & 0.271 & 0.278 \\ & 0.111 & 0.111 & 0.145 & 0.111\end{array}$


Normalisasi Matrik X berdasarkan persamaan.

$$
\begin{aligned}
& \mathrm{R}_{1.1}=\frac{0,611}{\operatorname{Max}\{0,611,0,278,0,111\}}=\frac{0,611}{0,611}=1 \\
& \mathrm{R}_{2.1}=\frac{0,278}{\operatorname{Max}\{0,611,0,278,0,111\}}=\frac{0,278}{0,611}=0.455 \\
& \mathrm{R}_{3.1}=\frac{0,111}{\operatorname{Max}\{0,611,0,278,0,111\}}=\frac{0,111}{0,611}=0.182 \\
& \mathrm{R}_{1.2}=\frac{0,611}{\operatorname{Min}\{0,611,0,278,0,111\}}=\frac{0,611}{0,111}=5.505 \\
& \mathrm{R}_{2.2}=\frac{0,278}{\operatorname{Min}\{0,611,0,278,0,111\}}=\frac{0.278}{0,111}=2.505 \\
& \mathrm{R}_{3.2}=\frac{0,111}{\operatorname{Min}\{0,611,0,278,0,111\}}=\frac{0.111}{0,111}=1 \\
& \mathrm{R}_{1.3}=\frac{0,457}{\operatorname{Max}\{0,457,0,257,0,157\}}=\frac{0,457}{0,457}=1 \\
& \mathrm{R}_{2.3}=\frac{0,257}{\operatorname{Max}\{0,457,0,257,0,157\}}=\frac{0,257}{0,457}=0,562 \\
& \mathrm{R}_{3.3}=\frac{0,157}{\operatorname{Max}\{0,457,0,257,0,157\}}=0.344 \\
& \mathrm{R}_{1.4}=\frac{0,611}{\operatorname{Max}\{0,611,0,278,0,111\}}=\frac{0,611}{0,611}=1 \\
& \mathrm{R}_{2.4}=\frac{0,278}{\operatorname{Max}\{0,611,0,278,0,111\}}=\frac{0,278}{0,611}=0.455 \\
& \mathrm{R}_{3.4}=\frac{0,111}{\operatorname{Max}\{0,611,0,278,0,111\}}=\frac{0,111}{0,611}=0.182 \\
&
\end{aligned}
$$

Sehingga diperlukan matrik normalisasi R sebagai berikut:

$$
\begin{array}{cccccc} 
& 1 & 5.505 & 1 & 1 & \\
\mathrm{x} & 0.455 & 2.505 & 0.562 & & 0.455 \\
& 0.182 & 1 & 0.344 & & 0.182
\end{array}
$$

Proses perangkingan dengan menggunakan bobot preferensi yang telah ditentukan $\mathrm{w}=[0,521,0,271,0,145,0,063] \quad$ berdasarkan persamaan normalisasi sebagai berikut:

$\mathrm{A} 1=(0,521)(1)+(0,271)(5,505)+(0,145)(1)+(0,063)($ $1)=2.221$

$\mathrm{A} 2=(0,521)(0,455)+(0,271)(2,505)+(0,145)(0,562)$ $+(0,063)(0,455)=1.026$

$\mathrm{A} 3=(0,521)(0,182)+(0,271)(1)+(0,145)(0,344)+(0$, $063)(0,182)=0.427$

Nilai terbesar ada pada A1 adalah alternatif terpilih sebagai alternatif terbaik sebagai pembukaan jaringan trayek angkutan kota.

\section{Implementasi Sistem}

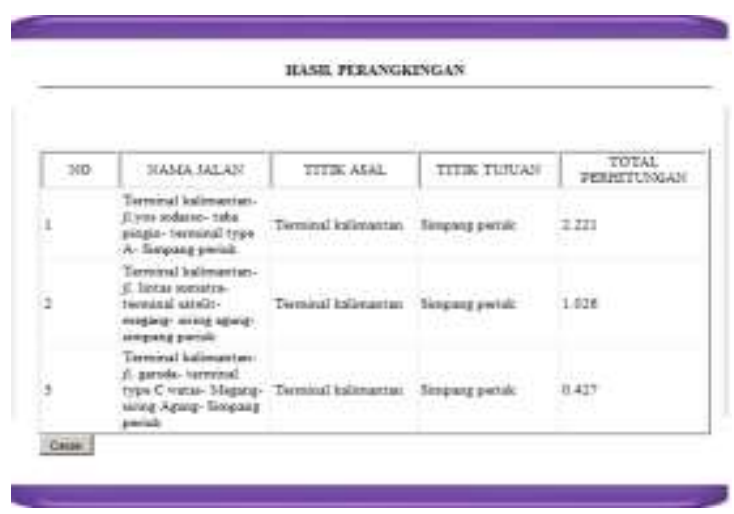

Gambar 8. Halaman Hasil Perhitungan

Pada gambar 8 diperoleh hasil perhitungan dengan menggunakan sistem yang telah dibangun. Dimana pembukaan jaringan trayek angkutan kota yang layak untuk dibangun adalah terminal Kalimantan tujuan simpang periuk dengan nilai 2,221.

\section{Kesimpulan}

Setelah

penulis

berhasil mengimplementasikan Sistem Pendukung Keputusan Pada Dinas Perhubungan Komunikasi dan Informatika Kota Lubuklinggau dengan metode SAW (Simple Additive Weighting)dan menggunakan bahasa pemrograman PHP dan Database $M y S Q L$, maka dapat diambil beberapa kesimpulan, yaitu:

1) Sistem yang dihasilkan Sistem Pendukung Keputusan Pembukaan jaringan Trayek Angkutan Kota Dinas Perhubungan Komunikasi dan Indormatika Kota Lubuklinggau.

2) Setelah aplikasi selesai maka penulis mencoba menerapkan sistem dan mencobanya dengan tiga alternatif sesuai dengan data yang ada pada Dinas Perhubungan Komunikasi dan Informatika Kota Lubuklinggau, setelah dilakukan perhitungan manual dan menggunakan aplikasi yang telah dibuat hasil akhir dari perhitungan manual dan pada sistem memiliki nilai yang sama sehingga dapat di simpulkan bahwa sistem yang telah di buat oleh penulis ini nantinya bisa meningkatkan kualitas dari keputusan yang akan diambil oleh kepala dinas.

\section{Saran}

Sistem pendukung keputusan pembukaan jaringan trayek angkutan kota ini masih memiliki banyak kekurangan, oleh sebab itu penulis berharap sistem pendukung keputusan pembukaan jaringan 
trayek ini dapat dikembangkan lebih lanjut demi tercapainya hasil sesuai dengan yang diharapkan. Untuk itu penulis memberikan bebrapa saran sebagai berikut:

1) Untuk pengembangan selanjutnya diharapkan kriteria seleksi untuk pembukaan jaringan trayek ini ditambah lagi, agar sistem pendukung keputisan ini dapat menghasilkan dukungan keputusan yang lebih baik lagi.

2) Untuk pengembang selanjutnya diharapkan dapat menjadi sistem pakar untuk pembukaan jaringan trayek angkutan kota sehingga dapat membantu kepala dinas dalam proses pengambil keputusan yang lebih spesifik.

\section{DAFTAR PUSTAKA}

[1] Kadir A, 2014, Pengenalan Sistem Informasi Edisi Revisi, Andi Offset: Yogyakarta.

[2] Kusumadewi Sri,dkk.2007, Fuzzy Multi Attributen Decision Making (FUZZY MADM), Graha Ilmu : Yogyakarta.

[3] Rosa, A.S dan M. Shalahuddin., 2013, Rekayasa Perangkat Lunak Terstruktur dan Berorientasi Objek, Inormatika :Bandung.

[4] Rahma A, 2013, Sistem Pendukung Keputusan Seleksi Masuk Mahasiswa Menggunakan Metode Smarter, Universitas Pendidikan Manusia,Repository.upi.edu,Perpustakaan.upi .edu.

[5] Sherly Setya Ningrum, D., 2014, Sistem Informasi Penjualan Barang Pada CV Karya Dempo Lubuklinggau, Tugas Akhir, DIII, STMIK Bina Nusantara Jaya Lubuklinggau.

[6] Wibowo S, H., 2009, Sistem Pendukung Keputusan Untuk Menentukan Penerima Beasiswa BANK BRI Menngunakan FMADM, SNATI 2009, 20 Juni 2009, 1907-5022 
